\title{
From Scraps to Reams: A Survey of Printing Services in Academic Libraries
}

\section{Beth Ashmore and Sara E. Morris}

\begin{abstract}
The growing number of electronic resources available in libraries has led to the adoption of printing as an integral part of library services. However, the high costs associated with providing printing have led many libraries to charge a printing fee. This article explores how academic libraries in the Southeastern United States are grappling with providing printing services both economically and equitably. The research finds that nearly half of the libraries surveyed are currently charging for printing, with another quarter considering charging in the future. Although no institutional characteristics appear to accompany a printing fee, the research finds that extensive planning and campuswide collaboration are essential components for the successful implementation of a fee-based printing system.
\end{abstract}

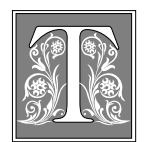

he personal computer has brought numerous changes to the academic library. Computers have taken up residence in the space that card catalogs once called home and have brought with them a wealth of primary and secondary sources. Yet, just as scraps of paper once were used by patrons to transport information from the card catalog to the shelf, libraries still need to provide a way for patrons to take the information from the computer and out into the world. When the computer replaced the card catalog, it was only a matter of time before the printer moved in as well.

The OPAC, one of the first public electronic resources, required little paper. Patrons could either write the call number on scrap paper or simply print out the citation on a dot matrix printer. Increasingly, electronic formats became both a popular and advantageous means of delivery for all kinds of resources. Database citations, which once were as small as a catalog record, evolved into ASCII fulltext articles. The ASCII forms of full text grew to include embedded photographs and illustrations. Highly graphical documents required a new format-portable document files, or PDFs. In addition to databases, e-journals and Web sites became legitimate sources for research and thus found a home in the academic library's reference room. Dot matrix printers were no longer able to print with the speed or the quality required by these new formats, and printing on quicker and costlier laser printers became a larger part of libraries' services. Scraps of paper no

Beth Ashmore is an Instruction Services Librarian and Assistant Professor at Mississippi State University; e-mail: bashmore@library.msstate.edu. Sara E. Morris is a Reference Services Librarian and Assistant Professor at Mississippi State University; e-mail: smorris@library.msstate.edu. 
longer were sufficient; libraries now relied on reams of paper to satisfy patron demand. This change has taken place very quickly and has left academic libraries with little time to prepare. Instead, libraries have been left to cope with a full recycling bin and the high cost of toner.

Any librarian or library patron will acknowledge that printing is an essential part of patron services in the modern academic library due to the prevalence of ejournals, e-books, and other full-text sources. Librarians have accepted this service as just as necessary as properly shelved books. Yet, the topic of printing has made few appearances in the literature. The few articles that do exist relate the experiences of one particular library and how it has come to handle charging for printing. Other articles simply give guidance on why and how to charge; thus, many questions remain. Who is charging? How much? Why are they charging?

\section{Any librarian or library patron will acknowledge that printing is an essential part of patron services in the modern academic library due to the prevalence of e-journals, e- books, and other full-text sources.}

This article seeks to recognize the current trends in academic library printing and to give guidance to those currently grappling with the how and why of providing printing services. The main problem this research seeks to solve is the lack of information on how libraries of all sizes, funding sources, and academic levels are dealing, both successfully and unsuccessfully, with the high cost of printing services. Using a survey of SOLINET libraries as a representative group of academic institutions, this article demonstrates the varied approaches currently being used to provide printing services to library users.

\section{What's the Problem with Printing?}

Modern academic libraries are a far cry from the paperless society that many projected the personal computer would bring. As always, libraries are in the busi- ness of not only providing information to users, but also giving them the tools necessary to take the information with them. Patrons have come to expect to be able to check out materials and make photocopies, and librarians struggle with how they can meet this patron demand in the most efficient and fair way possible. Printing has been added to the library's list of essential services. The major printing problems faced by libraries can be divided into three categories: finance, ecology, and access.

\section{Finance}

The cost of providing printing to patrons is much greater than just purchasing a printer. Software and hardware issues make it necessary to have additional products just to make the printer work, particularly when implementing a copy card or account system to manage print fees. In addition, as electronic resources change, printers must be upgraded to take full advantage of the new technology. For example, some databases are adding color PDFs, thus raising the question: Will library patrons soon expect color printers? If so, libraries will need to make another transition in printing services or face user dissatisfaction. After a printer is installed, there are many additional costs. The cost of paper and toner can add up quickly. Although it is possible to make predictions of what these items might cost and budget accordingly, the final expenditure depends on patron usage.

Besides the obvious financial aspects, there are a number of hidden costs. Staff take time away from more productive tasks to remove a paper jam, change toner, or add paper. This loss in productivity causes other areas of the library to suffer. Reference staff, for example, could spend more time answering questions if they did not have to deal with printer problems. Maureen A. Lindstrom and Andrew J. Dutcher wrote that the most popular questions at Buffalo State College's E. H. Butler Library in the late 1990s requested help in fixing printer problems. The librarians in that same library also felt that 
they spent 60 percent of their time taking care of printing issues. ${ }^{1}$ Clearly, librarians and library staff can lose valuable time dealing with printers.

\section{Ecology}

Although the financial issues caused by printing are a major concern to librarians, so too are the ecological effects. Walking by most printers in an academic library, one will see a number of unclaimed sheets of paper. In 1997, Betsy Park concluded that patrons probably do not intend to be wasteful but simply print far more than they need. ${ }^{2}$ In addition to the environmental impact of paper, toner cartridges are an ecological concern. Technology has made some recycling possible, but even with this ability, cartridges represent a formidable presence in a landfill. These ecological issues are particularly significant because library staff must consider them in their own day-to-day printing habits, in addition to encouraging ecologically conscientious printing in the user population.

\section{Access}

Whereas financial and ecological issues deal with the waste that printing can cause, there are ethical issues that make this decision difficult. Libraries have been charging for photocopies since photocopiers arrived. Patrons know this and willingly pay the fees necessary to take an article home. Since printers first arrived in libraries, many have charged from the beginning, viewing this service as roughly the same as photocopying; others feel that printing fees can create barriers to access. In "Questions and Answers: Access to Electronic Information, Services, and Networks: An Interpretation of the Library Bill of Rights," the ALA stressed that all services should be provided free of charge, if possible, with access to the resource being the primary goal. In this interpretation, making information available on the screen, but requiring patrons to pay to have a paper copy is acceptable in this technological age. ${ }^{3}$ Although the Library Bill of Rights does make allowances for fees, printing may be a more complex issue than charging for photocopies.

\section{Advantages of a Printing Fee}

In the literature on this subject, no single advantage stands out as the overwhelming reason to implement a printing fee. Institutions that have chosen to charge a fee usually cite multiple factors that contribute to the need for, and the advantage of, implementing a fee. The following represent the most common reasons for charging a fee and are often the rationale behind bringing such a fee into an academic library.

\section{Cost Recovery}

Cost recovery is a primary motivation for charging a printing fee. Many libraries no longer can afford to subsidize printing in light of the wealth of resources that are only available via electronic format. The income generated from a fee also can work toward paying the day-to-day paper and toner costs as well as freeing up funds to keep equipment up-to-date and functioning properly. Dale J. Vidmar, Marshall A. Berger, and Connie J. Anderson rationalized that if the money currently allocated to subsidizing printing were used to enhance other services, such as database access or increased materials and staff budgets, the benefits could far outweigh a small per-page fee. ${ }^{4}$

\section{Equalizing Print and Electronic Resources}

Users' desire to take the path of least resistance is a disturbing trend that is only made more troubling by the double standard between printing and photocopying. By charging for photocopying of noncirculating materials such as journals, reference materials, and microforms, but not charging for these same types of materials in electronic format, the library creates an inadvertent supremacy of electronic resources over print, regardless of actual content. Park summed up this argument perfectly: "If a library provides free printing from electronic resources, but charges for photocopies, it encourages 
users to select information based on format rather than quality or relevance. ${ }^{\prime 5}$

\section{Combating Waste}

Although some studies have found that many students are very concerned and conscientious in their printing habits, most of the literature discusses printer abuse as a major concern for libraries. ${ }^{6} \mathrm{~A}$ study at George Washington University found that 25 percent of the paper in the computer labs was recycled immediately. ${ }^{7}$ Even though this study dealt with university computer labs rather than library reference labs, it makes a strong argument in favor of using a fee to make patrons more careful before they choose to print.

Implementing the hardware and software necessary to charge for printing is not without its own costs and presents yet another system with which staff must be familiar to troubleshoot and maintain, even when services are outsourced. ${ }^{15}$

\section{Managing Resources}

Some of the literature on this subject advocates the use of a reserve model, providing users a reserve of free printing each semester. This system affords the library the ability to set limits on free printing while still offering students a subsidized service. ${ }^{8}$ This type of system encourages users not only to think carefully before they print, but also to manage consciously their printing resource, just as they would their time or money. As one participant from the EDUCAUSE CIO Constituent Group stated, "They do get something free, so they will benefit. We are an educational institution, so why not help teach prioritization, cost-benefit, and resource management skills?"9

\section{Disadvantages of a Printing Fee}

The disadvantages of charging for printing are formidable and range from driving users away from the library to violating the aforementioned ALA Library Bill of Rights. Unlike the advantages associated with implementing fees, any one of these arguments can prove to be enough to make printing fees untenable for an academic library.

\section{Barring Access}

Most discussions of this issue address the possible violation of Articles I and V of the ALA Library Bill of Rights, which are interpreted to state that libraries should remove all potential barriers to providing equitable access to information. Although the comparison to photocopying costs is often made, the ethical consideration becomes whether the printing fee can actually be seen as an equitable barrier. ${ }^{10}$ In the library setting, photocopy fees are fairly evenly borne by users. With many electronic resources available from anywhere Internet access is provided, users with access to personal computers and printers are less subject to this barrier than those who have less technology at their disposal and thus are more at the mercy of the library's resources and fees. ${ }^{11}$ With equal access for all users being one of the library's primary missions, serious thought regarding a printing fee is necessary.

\section{Dissatisfying Users}

Probably the greatest concern with implementing a printing fee is that of justifying charging for something that was once free. Even when users do not expect the service to be free, a library must consider the animosity that charging for printing can generate, especially if other campus labs offer free printing or if a technology fee is assessed for students. ${ }^{12}$ Even the Association of College and Research Libraries (ACRL) advocates that students consider printing fees when evaluating libraries at prospective universities and colleges. ${ }^{13}$ The need to establish a good relationship with users may outweigh the need to recover printing costs.

\section{Discouraging Library Use}

Another concern associated with the proliferation of electronic resources is the decreasing use of physical library resources in favor of remote access. Some 
studies have shown or predicted dramatic decreases in the use of printing services after fees were implemented. ${ }^{14}$ The concern is that the added barrier of a printing fee will push users further away from the library and toward other personal and campus resources.

\section{Funding More Infrastructure}

Implementing the hardware and software necessary to charge for printing is not without its own costs and presents yet another system with which staff must be familiar to troubleshoot and maintain, even when services are outsourced. ${ }^{15}$ Most studies agree that before implementing a fee-based printing service, a costbenefit evaluation is necessary to determine how long it will take to recover the initial start-up costs, taking into account the fact that printing may decrease with the fee in place. ${ }^{16}$

\section{Review of the Literature}

The current literature dealing with printing issues in libraries is fairly limited. Many articles deal with specific libraries' experiences with implementing a feebased system. These articles provide practical information on the tools necessary to adopt such a system and some discussion of the planning process. Authors such as Park approach the issue from a theoretical and practical standpoint, giving background on the issues that libraries currently face. The research on printing falls into two categories: surveys such as the 1999 Association of Research Libraries (ARL) SPEC Kit 254, Managing Printing Services and articles dealing with user perceptions of fee-based systems. In addition to the literature dealing specifically with library printing services, there are articles on the best way to manage public printing resources in an academic setting.

Vidmar, Berger, and Anderson documented the implementation process for Southern Oregon University. This example demonstrates a selective charging structure, where only full-text printing is subject to fees as opposed to catalog citations and index records. ${ }^{17}$ Tom Moothart and Lindsey Wess described the process that Colorado State University (CSU) went through in order to recoup costs and discourage excessive printing. The CSU example underscores the need for planning and publicity when attempting to start a successful fee-based program. ${ }^{18}$ Additional articles examine the benefits and drawbacks of outsourcing printing services to vendors. ${ }^{19}$

Park, unlike many authors, has taken a theoretical approach to printing in academic libraries. Many libraries, she has argued, have no idea how much they spend on printing because of the way budgets are created. The ambiguity of the total money spent makes justifying the implementation of a pay-for-printing system difficult. For this reason, adopting such a system is not something to rush into. Park also has stressed that the printing problems faced by libraries will not go away. Like photocopiers, printers are going to be around for a long time and libraries and their administrators must come up with policies and plans for their effective use. ${ }^{20}$

The actual establishment of a pay-forprinting system has been the topic of the majority of the literature. Murray S. Martin and Betsy Park, in Charging and Collecting Fees and Fines: A Handbook for Libraries, provide practical advice. This handbook contains such useful tools as a checklist and a worksheet that libraries can use to organize a charging system. ${ }^{21}$

Research on user perceptions of printing fees is slight. Richard L. Hart, John A. Olson, and Patience L. Simmonds examined students' feelings about the possibility of charging a fee for new laser printing services at Pennsylvania State University-Erie. In the end, a fee was not charged because of an existing computer fee and a strong student response that a fee would be seen as excessive. ${ }^{22}$

Although all of these articles talk about how and why a library might implement printing service charges, only one current source deals with data on how libraries overall are actually handling the problem. The 1999 ARL SPEC Kit 254, Managing 
Printing Services, contains details dealing with printing in ARL libraries, but this source is limited in scope to the largest academic research libraries. ${ }^{23}$ Another survey published on the Internet by the University of Richmond Law Library sheds some light on the variety of systems and structures being used to track and charge for printing. However, this survey too is limited because it deals with a very specialized group of users, namely, law students and lawyers. ${ }^{24}$

The overall need for printing resource management in academic environments is another important aspect of the library printing issue. The amount of wasted paper on college campuses has been a topic in printing literature. Steven Gnagni reviewed a number of different printing solutions for University Business. Like Park, Gnagni indicated that few schools really know the problems plaguing their current printing situation..$^{25}$ EDUCAUSE, an association of higher education institutions working to promote information technology, had an electronic discussion about printing in 1998. Although this discussion focused on campuswide printing, the issues and solutions brought forward gave librarians a glance at the information technology professionals' perspective. This discussion stressed the politics of a system and the different models used to charge students. ${ }^{26}$

\section{Methodology}

The authors created a survey instrument to find out how academic libraries are dealing with printing in reference computer labs. The survey asked for quantitative data on the number of computers and printers in reference areas as well as the amount of fees charged, if any. Questions also sought to learn the reasons for fees, how fees were collected, and, for those not charging, whether fees were being considered for the future. Libraries also were asked how long they had been charging and whether fees had reduced the amount of printing being done. Other questions included the use of limits, e-mail, software, reserve systems, policies, and cost studies to alleviate printing problems.
The survey was mailed in the summer of 2001 to all Southeastern Library Network, Inc., (SOLINET) academic members that grant degrees equaling a bachelor's or higher. Libraries serving institutions that grant bachelor's degrees or higher were seen as having communities with the greatest research needs and those likeliest to have the most access to electronic resources and the printing of those resources.

\section{Libraries at all levels and sizes are implementing or contemplating fees for the future.}

SOLINET is a regional library cooperative with members from Alabama, Florida, Georgia, Kentucky, Louisiana, Mississippi, North Carolina, South Carolina, Tennessee, Virginia, Puerto Rico, and the Virgin Islands. Currently, it is the largest organization of its kind in the United States. ${ }^{27}$ The authors targeted SOLINET libraries because of the diversity within this large group. A number of public and private institutions are members, including eighteen Association of Research Libraries' (ARL) members. The states in the cooperative also are representative of the variance in economic support that exists for higher education. In addition, the sizes of these institutions range from very small colleges of five hundred students to large research institutions with more than 30,000 students. Overall, the academic libraries that hold membership in SOLINET provide a good cross section of the various kinds of academic institutions in the United States.

The authors mailed a total of 329 surveys. The surveyed population consisted of 188 private institutions (57\%) and 141 public colleges or universities (43\%). The response rate was 57 percent (189 responses), with 111 responses from private institutions (58\%), 73 from public colleges and universities $(39 \%)$, and 5 from unspecified institutions (3\%).

\section{Results}

The results of the survey shed some light on what are currently the most popular 
TABLE 1

Type of Printing Services by Funding Source

\begin{tabular}{lccc}
\hline \hline & Charging & Considering & Not Considering \\
\hline All respondents $(\mathrm{n}=189)$ & 93 & 48 & 48 \\
Public institutions $(\mathrm{n}=73)$ & 45 & 17 & 11 \\
Private institutions $(\mathrm{n}=111)$ & 46 & 28 & 37 \\
Unspecified $(\mathrm{n}=5)$ & 2 & 3 & 0
\end{tabular}

solutions for printing but also indicated that no division of this community is embracing any single method. As shown in table 1, ninety-three of the libraries surveyed are charging for some form of printing (laser, inkjet, or dot matrix). Of those currently charging, forty-five are public institutions, forty-six are private institutions, and two are unspecified. Of the ninety-six institutions that are not currently charging, forty-eight responded that they are considering charging in the future. Fifteen percent of public institutions and 33 percent of private institutions either currently have no plans to charge for printing in the future or are unsure.

Institution size did not appear to play a large role in dictating whether a printing fee was used. The most notable trend is that the larger the university, the greater the certainty that a fee is being considered or is currently in use. The largest group of respondents, those institutions with 1,000 to 5,000 students, is almost evenly divided, with forty-one libraries charging and fifty-five not charging (table 2). Of the fifty-five libraries not charging, thirty are considering doing so in the future. Every grouping of institutions with more than 5,000 full-time students has a higher percentage of both charging libraries and those considering it for the future.

The level of degree programs at a particular institution also appears not to be a factor in predicting whether libraries are charging. As shown in table 3, the statistics for institutions granting bachelor's degrees, master's degrees, and doctorates break down similarly to the public and private institution statistics in table 1, with approximately half of each group already having implemented a fee and approximately one quarter of each group considering it for the future.

The per-page fees being charged for laser printing vary widely, with the most common being $\$ 0.10$ and $\$ 0.05$ (table 4). A small number of libraries indicated that they charge for the use of dot matrix (1\%) and inkjet quality printing (5\%). Many

TABLE 2

Type of Printing Services by FTEs of Responding Institutions

\begin{tabular}{lcccc} 
FTE Enrollment & $\begin{array}{c}\text { Number of } \\
\text { Institutions }\end{array}$ & Charging & Considering & Not Considering \\
\hline $0-500$ & 10 & 4 & 3 & 3 \\
$501-1000$ & 32 & 16 & 3 & 13 \\
$1001-5000$ & 96 & 41 & 30 & 25 \\
$5001-10,000$ & 18 & 10 & 6 & 2 \\
$10,001-20,000$ & 15 & 7 & 5 & 0 \\
$20,000-30,000$ & 8 & 7 & 1 & 0 \\
$30,001-36,000$ & 3 & 3 & 0 & 2 \\
Unspecified & 7 & 5 & 0 & 48 \\
\hline Total & 189 & 93 & 48 & \\
\hline
\end{tabular}


TABLE 3

Type of Printing Services by Highest Degree Granted

\begin{tabular}{lccc} 
Degree & Charging & Considering & Not Considering \\
\hline Bachelor's & 20 & 15 & 16 \\
Master's & 39 & 22 & 22 \\
Doctorate & 34 & 11 & 10 \\
\hline Total & 93 & 48 & 48
\end{tabular}

institutions rely on copy card (35\%) and student accounts (24\%) to handle the collection of fees, and a good number of libraries (57\%) still use personnel at the reference desk or other service desks to collect these fees (table 5).

Multiple factors influenced the decision to implement a fee. Cost recovery (61\%) was the reason most often cited, with deterrence for exhaustive printing (53\%) a close second. Many respondents remarked that deterring printer abuse was extremely important because it was a source of frustration for both staff and other users (table 6).

Most charging libraries have been doing so for less than five years, with 17 percent indicating they have charged since the library began to offer printing. Of those who switched from free printing to fee-based printing, 44 percent wit- nessed a reduction in printing after they implemented the fee. Very few libraries have used cost-effectiveness studies (11\%) or policies (34\%) to investigate or govern printing, and even fewer are part of a campuswide initiative to standardize printing (17\%). Another approach, the reserve model, was used by only fourteen libraries.

\section{Discussion}

The printing issue has clearly catalyzed academic libraries into taking action to minimize both cost and waste, while providing the best access possible. This can be seen when comparing these results with those from the 1999 ARL Printing Services Survey. In that survey, more than half of those responding were charging fees $(60 \%)$, but far fewer were considering it for the future $(6 \%) .{ }^{28}$ Although the

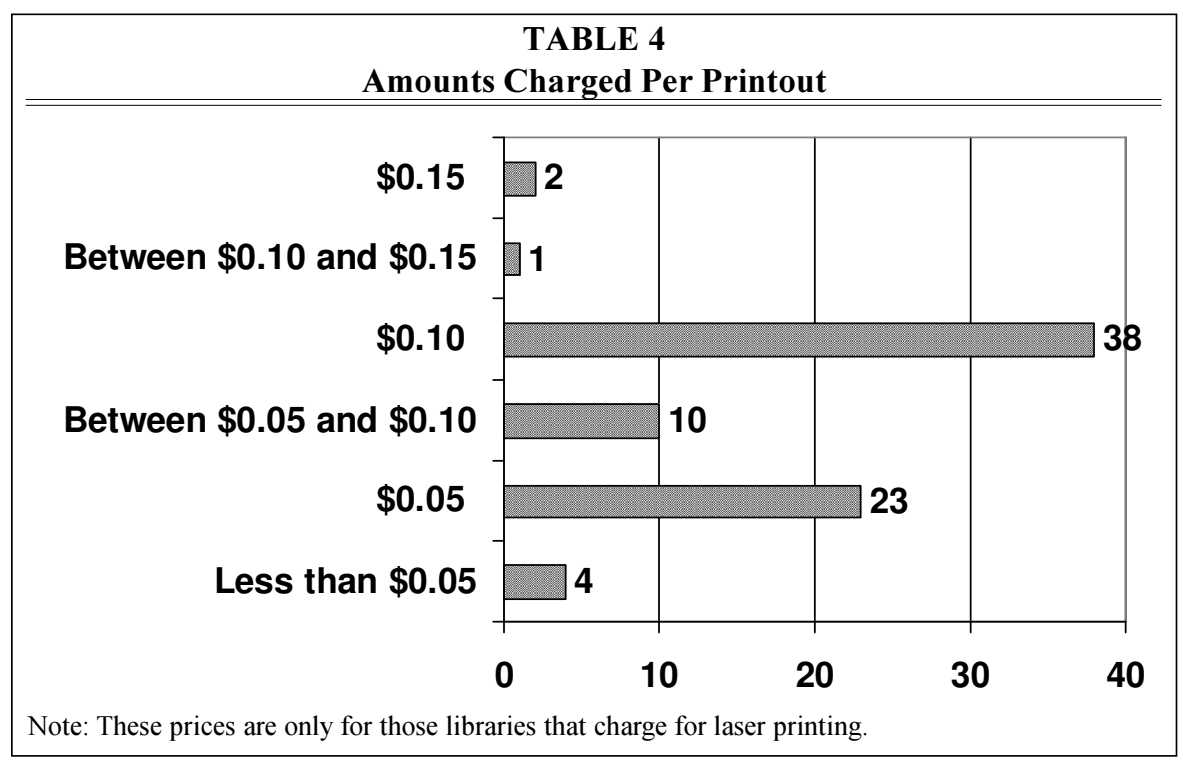




\begin{tabular}{|lcc|}
\hline \multicolumn{3}{|c|}{$\begin{array}{c}\text { TABLE 5 } \\
\text { Fee Collection Methods }\end{array}$} \\
\hline \hline Location & $\begin{array}{c}\text { Number of All Charging } \\
\text { Libraries (n = 93) }\end{array}$ & $\begin{array}{c}\text { Percentage of All } \\
\text { Charging Libraries }\end{array}$ \\
\hline $\begin{array}{lcc}\text { Reference desk } \\
\text { Other service desk }\end{array}$ & 16 & 17 \\
Copy card & 38 & 40 \\
Accounting system & 22 & 35 \\
Other & 4 & 24 \\
Note: Respondents were allowed to check all methods used.
\end{tabular}

the fee is necessary and how it will ultimately benefit the library by allowing it to provide increased services in other areas.

The respondents who spoke most favorably about their current situation were those who had worked with vendors and campus labs to organize a plan. Some respondents re-

percentage of charging institutions found by ARL and this survey is roughly similar, the increase in the percentage of institutions considering a fee for the future from 6 to 25 percent suggests that printing issues have become an even greater concern.

Another trend clearly visible in the data is that printing issues do not discriminate. Libraries at all levels and sizes are implementing or contemplating fees for the future. The number of libraries (nearly half) currently charging, along with another 25 percent of respondents considering implementing a fee, suggests that a per-page fee is a common solution. What appears to make the difference between success and failure are planning and collaboration.

The lack of institutions using cost-effectiveness studies to investigate charging a per-page fee suggests that printing issues are victims of a lack of time to devise a solution. This, combined with a lack of policies to govern printing services, leaves libraries without an overall plan, which is necessary for success in providing any service. Sufficient planning also is helpful in easing users into the fee-based process. Users must be given time to adjust to this process and all the information about why plied with a sense of gratitude for other campus units that facilitate the printing process: "the library staff appreciates the card center for all the work that they do to maintain a system that mostly runs smooth through the year. We also do what we can to troubleshoot some of the common maintenance problems." A library that outsources its printing services spoke to the ease that enlisting a vendor's help can provide: "We use a commercial vendor who services the copy card machines, the laser printers, etc. The vendor provides the machines and collects all the money. After years of doing it ourselves we finally got smart. Now it's virtually hassle free.... All queries and complaints are directed to students who are hired by [the vendor] to service the machines and patrons. A supervisor comes daily to check for special problems. If we have problems with printing, we page the supervisor."

Even for those libraries that are not charging a per-page fee, planning to share the financial burden of printing is impor-

\begin{tabular}{|lcc|}
\hline \multicolumn{3}{|c|}{ TABLE 6} \\
\multicolumn{1}{|c|}{$\begin{array}{c}\text { Reasons for Charging a Per-Page Printing Fee } \\
\text { Number of All Charging } \\
\text { Libraries (n=93) }\end{array}$} & $\begin{array}{c}\text { Percentage of All } \\
\text { Charging Libraries }\end{array}$ \\
\hline \hline Cost recovery & 57 & 61 \\
Breaking even & 15 & 16 \\
Campuswide policy & 20 & 22 \\
Deterrent for printing abuse & 49 & 53 \\
Other & 3 & 3 \\
& \\
Note: Respondents were allowed to check all applicable reasons
\end{tabular}


tant: "Paper is purchased by the university (not the library) through a technology fee paid by the students. Certainly works well for us." Many of the noncharging libraries indicated that their institutions' overall plan to streamline fees for the benefit of both students and staff has helped handle this issue: "The administration decided recently to eliminate as many 'small fees' as possible and compensate by raising the activity fee per semester. We decided to include printing fees in the list of eliminated charges. Overall, it has worked very well—saves library staff a lot of hassle." Finally, a comprehensive planning process will allow staff to become familiar with any new systems and will better prepare them to explain fees to users.

An essential part of the planning process is collaboration. Many of those surveyed who were unsatisfied with their current situation said it was due to the lack of a campuswide solution. The fear of charging and driving away users as well as the fear of being the only one not charging and thereby encouraging abuse are real issues that libraries must consider and work to remedy. Patrons are already inclined to use the resources in the comfort of their own homes and offices, so when they do seek out a public lab for services and assistance, the library needs to present as few barriers as possible. One library appeared to find this out the hard way: "We used to charge for printing, but we stopped when students began using computer labs with inadequate support, but free printing." Other libraries are currently waiting to implement a printing program: "[The] Information Technology department is actually responsible for funding free printing. Eventually, they hope to implement the use of some sort of 'smart card' system that will charge students for printouts.... In the meantime, tons of paper are needlessly wasted each year!!!" Even though the frustration caused by waiting for a campus infrastructure to be put in place may be overwhelming, the alternative of creating a library-specific policy is not seen as very favorable: "So far, we have been unsuccessful in seeking a campuswide solution to printing. We are unlikely to seek a library-only solution that would make us different from other units on campus." With the growing number of campus computer labs located within the library facility, it becomes imperative that the separate entities present a united front for both their benefit and that of their users. By providing one cohesive service, students become acquainted with a single policy that can govern their printing practices, regardless of where they are working.

Planning and collaboration are particularly useful when contemplating a reserve model system. The previously mentioned reserve model system appears to be a rather underused and advantageous option for both charging and noncharging libraries as well as for those libraries with technology fees that still do not seem to cover the cost of printing. The reserve system requires the same infrastructure as an account-driven, fee-based system but provides users with a predetermined number of free pages before charging a per-page fee. This system rewards conscientious users and deters printing abusers. All campuswide technology fee revenues can be used to pay for infrastructure costs and initial allocations of printing. The concern over the barrier to access for those without personal printing resources is less immediate. This system still encourages the use of electronic resources over print but makes it far more difficult for users to complete their education without consulting a single print resource. Although those responding libraries currently using a reserve system made no specific comment as to its success, the literature on the topic suggests that this option should be closely considered by libraries looking for a solution to their printing woes.

\section{Conclusion}

The printing problem is far from being resolved. Many areas for further research are available. Technological changes may provide greater allowances for charging for 
specific types of material and may offer increased capabilities in terms of managing how printing services are integrated into the overall campus infrastructure. Partnering with vendors and outsourcing many of these services appears to be another viable solution that allows libraries to focus on other areas of operation. This article concentrates on the trend toward charging a fee and the concerns associated with implementing a fee-based system, but, undoubtedly, many libraries that have implemented creative funding of these services are not charging. A survey of nonfee-based programs would be another area of research that could provide further guidance for those for whom a fee is not an option. Overall, although the printing problem is not resolved, there is much to be learned from the successes and failures of other libraries in finding the best way to make a library's resources portable.

\section{Notes}

1. Maureen A. Lindstrom and Andrew J. Dutcher, "A Marriage Made in Heaven: How We Chose Good Partners to Improve Our Printing Services," Computers in Libraries 21 (Jan. 2001): 44.

2. Betsy Park, "Charging for Printouts," The Bottom Line: Managing Library Finances 10, no. 4 (1997): 148.

3. American Library Association, "Questions and Answers: Access to Electronic Information, Services, and Networks: An Interpretation of the Library Bill of Rights" (Nov. 17, 2000), available online from http:/ / www.ala.org/alaorg/oif/oif_q\&a.html_(read 2 Jan. 2002).

4. Dale J. Vidmar, Marshall A. Berger, and Connie J. Anderson, "Fee or Free? Printing from Public Workstations in the Library," Computers in Libraries 18 (May 1998): 27.

5. Park, "Charging for Printouts," 150.

6. Richard L. Hart, John A. Olson, and Patience L. Simmonds, "Laser Printing at

Public Workstations: User Behaviors and Attitudes," Information Technology and Libraries 20 (Mar. 2001), available online from <http:/ / www.lita.org/ital/2001_hart.html> (read 2 Jan. 2002).

7. Steven Gnagni, "The Paper Chase," University Business 2 (Jan. /Feb. 1999): 60.

8. Ibid., 61.

9. EDUCAUSE, CIO Constituent Group, "CIO Digest on Printing Fees in Student Labs" (June 15, 1998), available online from <http:/ / www.educause.edu/page2/cio_printing_fees.html> (read 2 Jan. 2002).

10. Park, "Charging for Printouts," 149.

11. Vidmar, Berger, and Anderson, "Implementing a Cost Recovery System for Printing," Reference Services Review 25 (fall/winter 1997): 98.

12. Hart, Olson, and Simmonds, "Laser Printing at Public Workstations."

13. Association of College \& Research Libraries, "A Student's Guide to Evaluating Libraries in Colleges and Universities" (June 29, 2001), available online from <http:/ / www.ala.org/acrl/ evalguide.html> (read 2 Jan. 2002).

14. Vidmar, Berger, and Anderson, "Implementing a Cost Recovery System for Printing"; Tom Moothart and Lindsey Wess, "Popularity Has Its Costs," Colorado Libraries 25 spring 1999).

15. Moothart and Wess, "Popularity Has Its Costs," 17.

16. Park, "Charging for Printouts," 151.

17. Vidmar, Berger, and Anderson, "Implementing a Cost Recovery System for Printing."

18. Moothart and Wess, "Popularity Has Its Costs."

19. Lindstrom and Dutcher, "A Marriage Made in Heaven"; Ralph M. Daehn, "Launching a Public Printing Program with Built-in Cost Recovery," Computers in Libraries 20 (Oct. 2000).

20. Park, "Charging for Printouts."

21. Murray S. Martin and Betsy Park, Charging and Collecting Fees and Fines: A Handbook for Libraries (New York: Neal-Schuman Publishers, 1998).

22. Hart, Olson, and Simmonds, "Laser Printing at Public Workstations."

23. Julia C. Bilxrud, Managing Printing Services: A SPEC Kit (Washington, D.C.: Association of Research Libraries, 2000).

24. University of Richmond Law Library, "Law School Printing Survey" (Nov. 15, 2001), available online from <http:/ / law.richmond.edu/general/printsurvey.htm> (read 2 January 2002).

25. Gnagni, "The Paper Chase."

26. EDUCAUSE, CIO Constituent Group, "CIO Digest on Printing Fees in Student Labs."

27. SOLINET, "About SOLINET" (July 27, 2001), available online from <http:// www.solinet.net/about_us/about_us_home.cfm> (read 2 Jan. 2002).

28. Bilxrud, Managing Printing Services. 